\title{
Discovery of the genus Glyphicnemis Förster in the Oriental Region (Hymenoptera, Ichneumonidae, Cryptinae)
}

\author{
Tao Li', Mao-Ling Sheng', Kyohei Watanabe², Zheng-Fu Guo ${ }^{3}$ \\ I General Station of Forest Pest Management, State Forestry Administration, Shenyang 110034, P. R. China \\ 2 Kanagawa Prefectural Museum of Natural History, Iriuda 499, Odawara, Kanagawa 250-0031, Japan \\ 3 Jiangxi Forestry Society, Nanchang Jiangxi 330038, P.R. China \\ Corresponding author: Mao-Ling Sheng (shengmaoling@163.com)
}

Academic editor: B. Santos | Received 24 February 2017 | Accepted 9 May 2017 | Published 7 June 2017

http://zoobank.org/D0AA040E-1B80-4BD2-9E8E-D4EF6CCF50A7

Citation: Li T, Sheng M-L, Watanabe K, Guo Z-F (2017) Discovery of the genus Glyphicnemis Förster in the Oriental Region (Hymenoptera, Ichneumonidae, Cryptinae). ZooKeys 678: 129-137. https://doi.org/10.3897/zookeys.678.12397

\begin{abstract}
The genus Glyphicnemis Förster, 1869 is newly recorded from the Oriental Region based on a new species, Glyphicnemis ganica Sheng \& Li, sp. n., collected from Jiangxi Province, in the oriental part of China. This species resembles $G$. watanabei (Uchida, 1930) from Japan in the coloration of flagellum and the structure and colouration of metasomal tergites, but it can be distinguished by the density and length of clypeal setae, the large propodeal spiracle, and the sculpture of area superomedia. Illustrations of G. ganica and $G$. watanabei are provided. A key to the Asian species of this genus is also given.
\end{abstract}

\section{Keywords}

Glyphicnemis, key, new species, Phygadeuontini, taxonomy

\section{Introduction}

Glyphicnemis Förster, 1869, belonging to the tribe Phygadeuontini of the subfamily Cryptinae (Hymenoptera: Ichneumonidae), comprises 12 species (Yu et al. 2016), of which six are from the Eastern Palaearctic Region (Ghahari and Jussila 2014, Jonaitis 1981, Uchida 1930, 1952) (three of them are found across the Palaearctic), five from the Western Palaearctic Region (Ciochia 1973, Jonaitis 1981, Sawoniewicz 1985,

Copyright Tao Li et al. This is an open access article distributed under the terms of the Creative Commons Attribution License (CC BY 4.0), which permits unrestricted use, distribution, and reproduction in any medium, provided the original author and source are credited. 
Schwarz and Shaw 2010, Yu et al. 2016) and four from the Nearctic Region (Luhman 1986). One species of Glyphicnemis Förster was known from China (Uchida 1930). The diagnostic characters of the genus were most recently revised by Townes (1970).

Jonaitis (1981) provided a key to the species of the European part of USSR. Sawoniewicz (1985) revised the European species of the subtribe Endaseina with keys to the genera and the species of Glyphicnemis. Most Eastern Palaearctic species were described by Uchida (1930, 1952, 1955). A single species, G. satoi (Uchida, 1930), is previously recorded from Heilongjiang Province, Northeastern China.

In this article a new species of Glyphicnemis from Jiangxi, China, is described. This species is the first record of this genus from the Oriental Region.

\section{Materials and methods}

Specimens were collected with interception traps (IT) (Li et al. 2012) in Wugongshan National Natural Reserve, Pingxiang, Jiangxi Province, P.R. China. Type specimens are deposited in the Insect Museum, General Station of Forest Pest Management (GSFPM), State Forestry Administration, People's Republic of China.

The type specimens of Stylocryptus osakensis Uchida, 1930 (Holotype), S. satoi Uchida, 1930 (Lectotype), S. watanabei Uchida, 1930 (Lectotype), deposited in Hokkaido University, Japan, were examined and compared to the new species. Glyphicnemis atrata (Strobl, 1901), G. vagabunda (Gravenhorst, 1829) and G. profligator (Fabricius, 1775), deposited in Zoologische Staatssammlung München, München, Germany and identified by Sawoniewicz, were also compared to the new species.

Images were taken using a Stereomicroscope (Leica M205A) with a LAS Montage MultiFocus. Morphological terminology is mostly based on Gauld (1991).

\section{Taxonomy}

\section{Glyphicnemis Förster, 1869}

Glyphicnemis Förster, 1869: 181, figs 2,3,6,9,10.

Diagnosis. Eye surface usually with sparse, short hairs (Fig. 3). Clypeus very wide, apical margin thick. Lower tooth of mandible much longer than upper tooth (Fig. 2). Upper end of epicnemial carina reaching to subalar prominence. Scutoscutellar groove with strong median longitudinal carina (Fig. 6). Outer side and apex of tibiae with strong spines (Figs 9, 10). Apical truncation of hind tibia very oblique (Fig. 9). Spurs of hind tibia inserted distinctly before apex (Fig. 10). Median dorsal carina of first tergite strong. 
Key to species of Glyphicnemis recorded from Asia (Oriental and Eastern Palaearctic Regions) (Female only)

1 Propodeal spiracle small, semicircular, $1.3-1.5 \times$ as long as wide. Costula connecting area superomedia approximately at its middle. Tergites 2 and 3 usually reddish brown.

G. atrata (Strobl)

- $\quad$ Propodeal spiracle large, elongate, $1.5-2.1 \times$ as long as wide. Costula connecting area superomedia at its posterior portion (in $G$. profligator and $G$. vagabunda at midlength), or tergites 2 and 3 black

2 Flagellum red, apical portion brown-black, without white ring. Tergites (except base of first tergite which is black) and hind femur red-brown.

G. vagabunda (Gravenhorst)

- $\quad$ Flagellum with white ring (Fig. 4), at least dorsal median portion white. Anterior and posterior extremities of tergites black or brownish black (except $G$. profligator). Hind femur black, brown-black, red-brown, or light colored ...3 Hypostomal carina distinctly higher than genal carina. Area superomedia distinctly wider than its length..... G. profligator (Fabricius)

- Hypostomal carina almost as high as genal carina. Area superomedia almost as wide as long.....

Tergites 2 and 3 smooth, shiny, without punctures, or almost impunctate; black or brownish black.

- $\quad$ Tergites 2 and 3 more or less granulate, with fine punctures; red or darkish red-brown

Apical margin of clypeus with dense long hairs (Fig. 12). Propodeal spiracle large, elliptic. Area superomedia smooth (Fig. 13). Tergites darkish red-black. Median portion of hind tibia yellow G. watanabei (Uchida) Apical margin of clypeus without exceptional long hairs (Fig. 2). Propodeal spiracle elongate, $2 \times$ as long as wide (Figs 7, 8). Area superomedia (Fig. 11) with dense irregular transverse rugae. Second and subsequent tergites black (Fig. 1). Dorsal side of hind tibia darkish brown, ventral side yellow-brown (Figs 1, 9)

G. ganica Sheng \& Li, sp.n. Anterior portion of postpetiole with transverse rugae, posterior portion with longitudinal rugae. Lateral carinae of area superomedia very weak, costula connecting approximately at its posterior 0.25 . Tergites 2 and 3 darkish redbrown G. satoi (Uchida)

- $\quad$ Median portion of postpetiole smooth, almost unpunctate, lateral portion with sparse fine punctures. Lateral carinae of area superomedia strong, costula connecting almost at its middle. Tergites 2 and 3 red. G. osakensis (Uchida) 


\section{Glyphicnemis ganica Sheng \& Li, sp. n.}

http://zoobank.org/EEA5AC71-4536-40C1-961B-8D00C25F0124

Figs $1-11$

Type material. Holotype, female, Hongyangu, Wugongshan Natural Reserve, 530m, 24 May 2016, collected with IT by Yu Yao (GSFPM).

Diagnosis. Subapical portion of clypeus strongly convex, forming a transverse ridge, apical margin without exceptional long hairs (Fig. 2). Area superomedia with dense, irregular transverse rugae (Fig. 11). Propodeal spiracle large, elongate, approximately $2 \times$ as long as wide (Figs 7, 8). Second and subsequent tergites black (Fig. 1). Dorsal side of hind tibia darkish brown, ventral side yellow-brown (Fig. 9). First tergite dark brown, posterior portion of postpetiole red-brown. Second and subsequent tergites black.

Description. Female. Body length approximately $8.5 \mathrm{~mm}$. Forewing length approximately $6.0 \mathrm{~mm}$. Ovipositor sheath length $1.2 \mathrm{~mm}$. Head, mesosoma, and apical portion of metasoma with dense short yellowish brown hairs.

Head. With dense large punctures. Face $2.8 \times$ as wide as long, strongly convex. Clypeus $4.0 \times$ as wide as long (Fig. 2); basal portion with transverse rugae; subapical portion strongly convex, forming a transverse ridge. Basal portion of mandibles with longitudinal rugae and fine punctures; lower tooth $3.7 \times$ as long as upper tooth. Eye particularly small, with sparse short hairs. Malar space $0.4 \times$ as long as basal width of mandible. Gena in lateral view $1.4 \times$ as long as width of eye, with punctures larger than those of face. Vertex (Fig. 3) with dense uneven puctures. Postocellar line $1.2 \times$ as long as ocular-ocellar line. Antenna (Fig. 4) short, with 19 flagellomeres. Second flagellomere $1.25 \times$ as long as maximum width. Ratio of length from first to fifth flagellomeres: 1.4:1.0:0.9:0.8:0.7. Occipital carina complete.

Mesosoma. Anterior portion of pronotum laterally (Fig. 5) with dense irregular rugae and punctures; lateral concavity with uneven transverse rugae; upper posterior portion with large punctures. Epomia distinct. Mesoscutum (Fig. 6) shiny, with irregular punctures, postero-median portion with longitudinal rugae. Scutellum (Fig. 6) slightly convex, smooth, shiny, with sparse punctures. Upper portion of mesopleuron (Fig. 7) with dense, irregular punctures, lower portion with transverse rugae and irregular, indistinct punctures; lower posterior portion with oblique rugae. Speculum small, smooth, shiny. Metapleuron (Fig. 8) with strong, irregular reticulate rugae. Wings gray, hyaline. Fore wing with vein $1 c u-a$ distinctly distal of $1-M$. Areolet pentagonal. Distance from vein $2 r s-m$ to $2 m-c u$ slightly longer than distance from $2 m-c u$ to $3 r s-$ $m$. Vein $2-C u$ approximately $2 \times$ as long as $2 c u-a$. Hind wing vein $1-c u$ about $3 \times$ as long as $c u-a$; $1-c u$ strongly inclivous. Hind leg (Figs 9, 10) exceptionally stout. Hind femur $2.5 \times$ as long as its maximum width. Ratio of length of one to fifth hind tarsomeres 2.0:1.0:0.7:0.4:1.0. Propodeum (Fig. 11) with complete carinae. Area basalis shiny, with sparse fine punctures, strongly convergent posteriorly. Area superomedia hexagonal, with strong irregular transverse rugae, costula connecting approximately at its posterior 0.3 . Area petiolaris strongly slant, with irregular transverse rugae. Area 

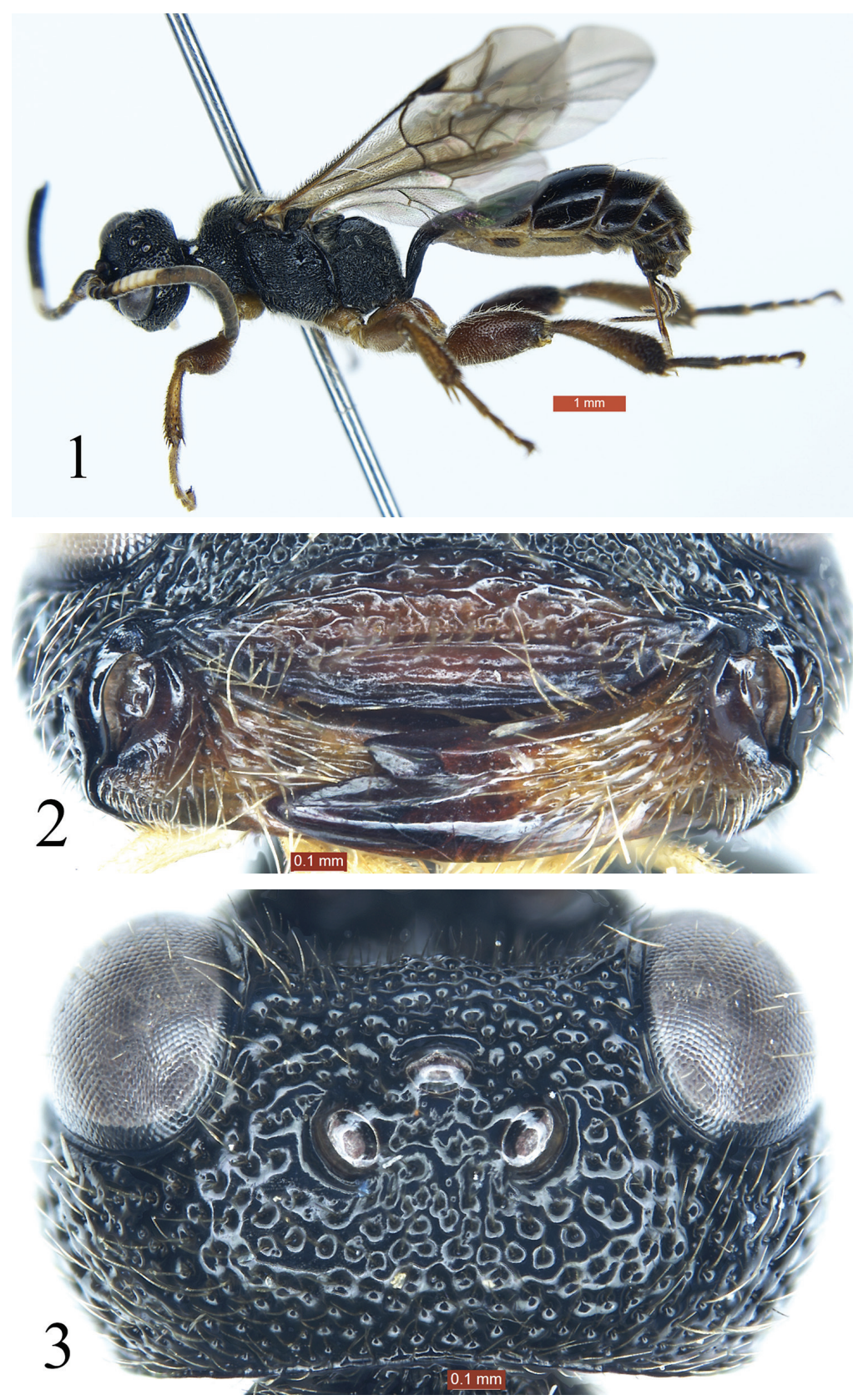

Figures I-3. Glyphicnemis ganica sp. n. Holotype. Female. I Habitus, lateral view 2 Clypeus and mandibles 3 Head, dorsal view.

externa shiny, with distinct, uneven punctures. Area dentipara and area lateralis with irregular reticulate rugae. Propodeal spiracle (Fig. 8) elongate, approximately twice as long as wide. 

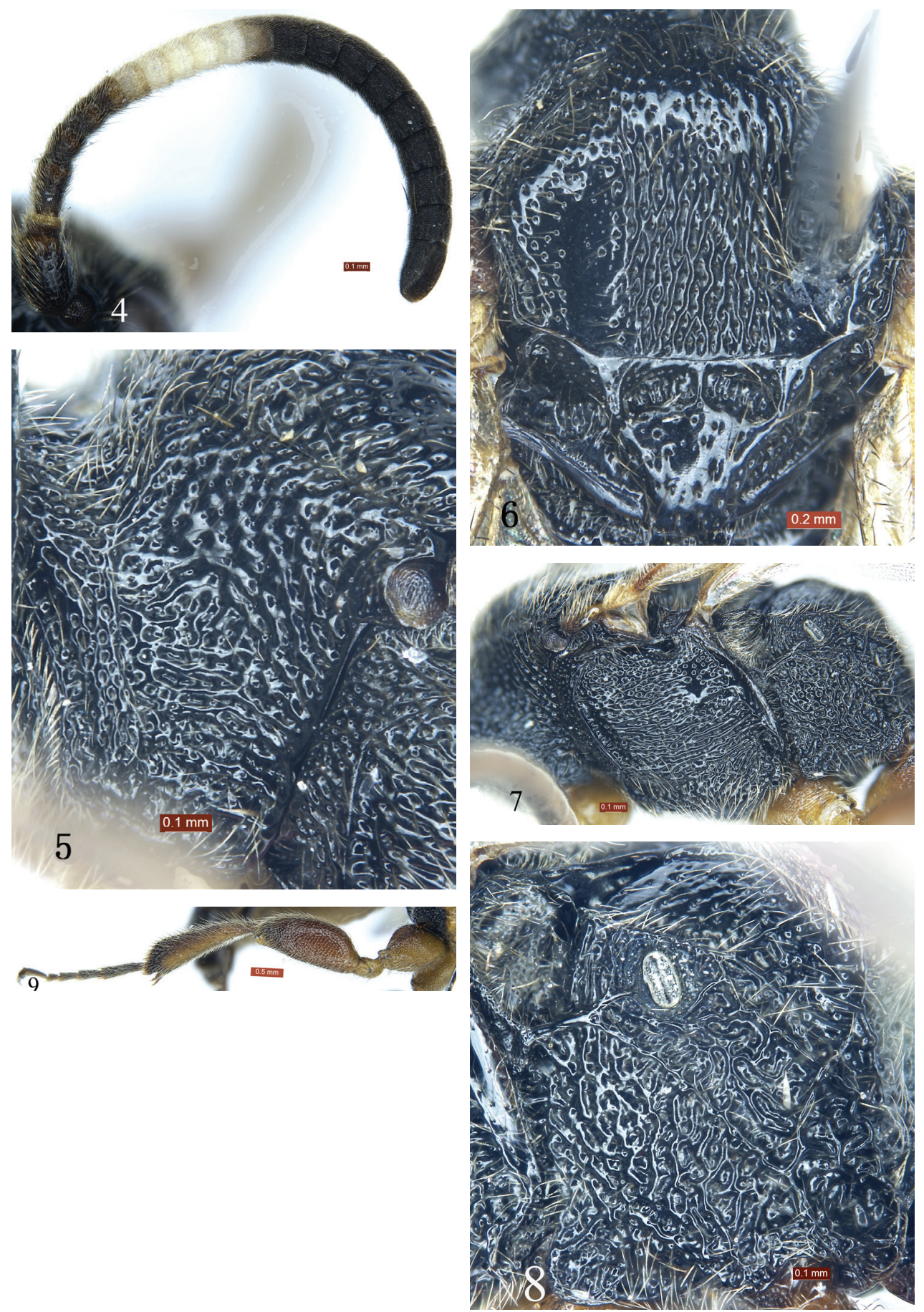

Figures 4-9. Glyphicnemis ganica sp. n. Holotype. Female. 4 Antenna 5 Pronotum, lateral view 6 Mesoscutum and scutellum 7 Mesosoma, lateral view 8 Metapleuron 9 Hind leg. 

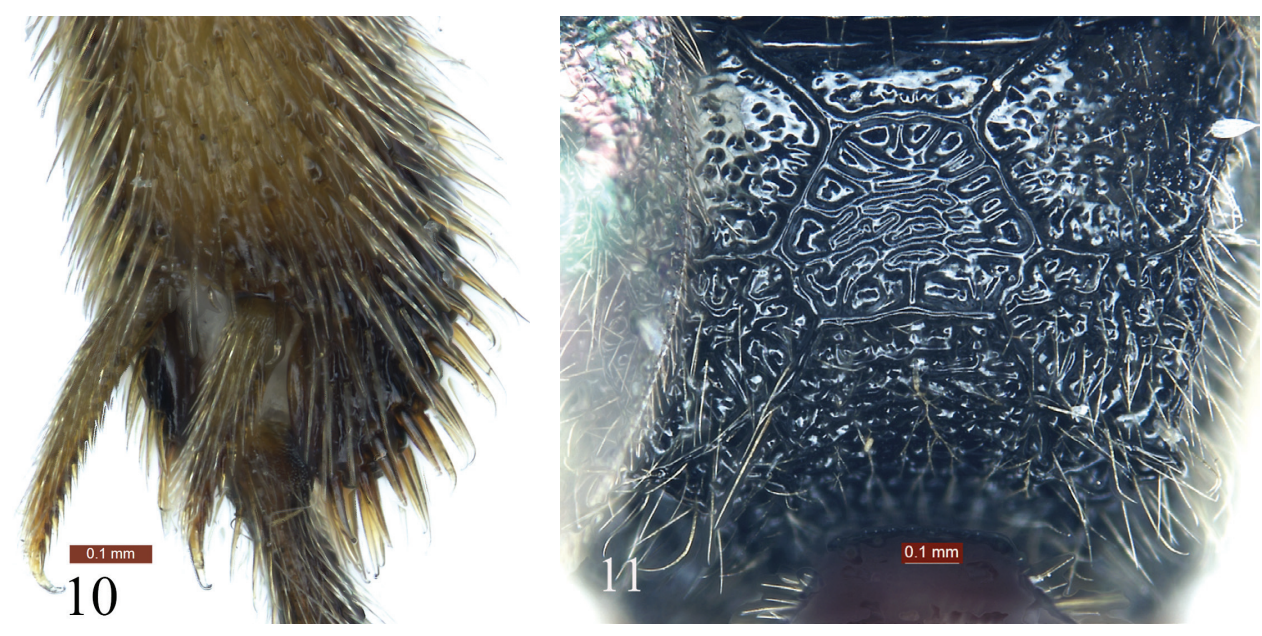

Figures I0-II. Glyphicnemis ganica sp. n. Holotype. Female. I0 Apical portion of hind tibia I I Propodeum.
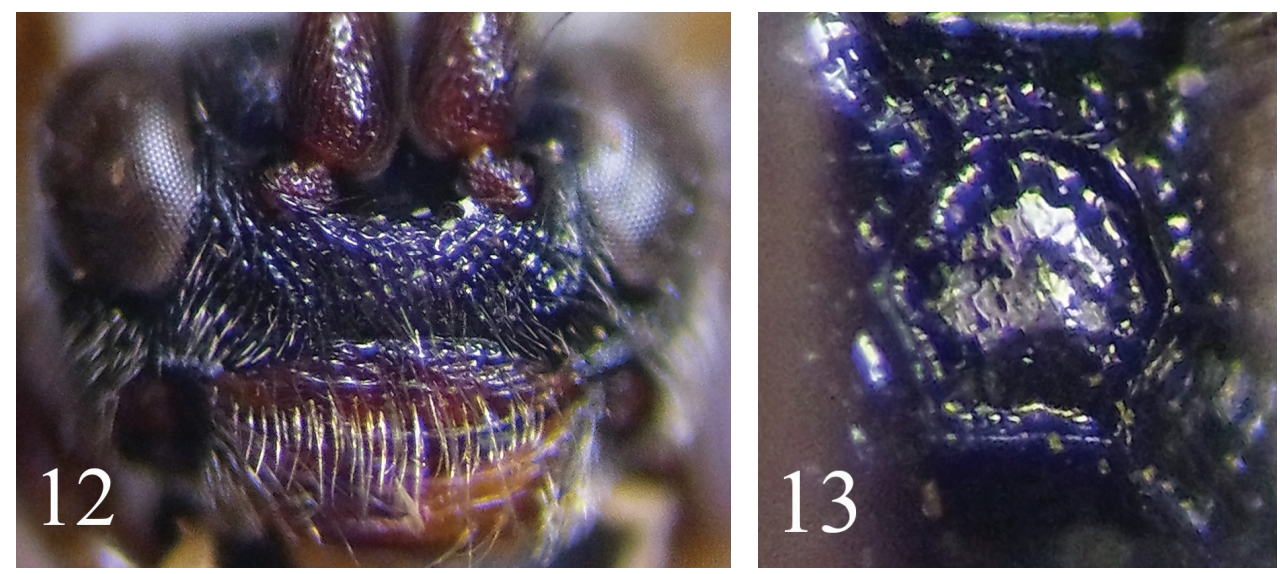

Figures I2-13. Glyphicnemis watanabei (Uchida, 1930). Holotype. Female. 12 Head, anterior view 13 Propodeum.

Metasoma. Tergites smooth, shiny. First tergite $1.7 \times$ as long as posterior width, median dorsal carinae reaching about 0.6 of first tergite; posterolateral parts with sparse fine punctures. Dorsolateral and ventrolateral carinae complete. Spiracle circular, small, located at posterior 0.3 of first tergite. Second tergite $0.56 \times$ as long as its posterior width, with a few indistinct fine punctures. Third tergite $0.7 \times$ as long as its posterior width, $0.8 \times$ as long as its posterior width. Fourth and subsequent tergites with short brown pubescence. Ovipositor sheath $0.9 \times$ as long as hind tibia.

Coloration (Fig. 1). Black, except for the following. Clypeus, mandibles except teeth, reddish brown. Maxillary and labial palpi fawn. Ventral side of scape and pedicel reddish brown. Ventral side of flagellum slightly brownish. Flagellomeres 5 to 9 white, 
ventral side narrowly slightly blackish. Dorsal sides of legs red-brown, ventral sides yellow-brown; apical portion of hind tibia and tarsi more or less brownish black. Tegulae and posterior portion of postpetiole red-brown. First tergite dark brown. Pterostigma and veins brownish black.

Remarks. This new species is similar to G. watanabei (Uchida, 1930) but can be distinguished from the latter by the following combination of characters: apical margin of clypeus without unusual long hairs (vs. with dense, long hairs; see Fig. 12). Area superomedia with strong irregular transverse rugae, costula connecting at its posterior 0.3 (vs. smooth, shiny, without rugae, costula connecting slightly beyond its middle; see Fig. 13). Ovipositor sheath $0.9 \times$ as long as hind tibia (vs. 0.75). Clypeus entirely reddish brown (vs. basally black, apically brown). First tergite dark brown (vs. black). All coxae and hind femur yellow brown (vs. black). It can also be distinguished from the known species of the Oriental and Eastern Palaearctic Regions by the preceding key.

Etymology. The specific name is derived from the type locality.

\section{Acknowledgements}

The authors are deeply grateful to Drs Bernardo Santos (Division of Invertebrate Zoology Richard Gilder Graduate School, American Museum of Natural History, USA), Martin Schwarz (Biologiezentrum, Linz, Austria) and one anonymous referee for reviewing this manuscript. The authors are also indebted to Dr. Dicky S. K. Yu (Canadian National Collection, Ottawa, Canada) for presenting valuable material, and Mr. Yu Yao (Wugongshan Natural Reserve, Pingxiang, Jiangxi Province, China) and Prof. Yan-Ping Liang (Pingxiang forestry Pest Management and quarantine Bureau, Pingxiang, Jiangxi Province, China) for their help in the course of exploration in Wugongshan Natural Reserve, Pingxiang, Jiangxi. This research was supported by the National Natural Science Foundation of China (NSFC, No. 31501887, No. 31372246, No. 31070585) and Discipline Development Research Project of Chinese Society of Forestry in 2015.

\section{References}

Ciochia V (1973) De nouvelles espèces pour la science des Trachysphyroides, découvertes dans la zone du "Portile de Fier" ansi que dans la "Reserve des Dunes d'Agigea". Lucrarile Statiunii Stejarul Ecologie Terestra si Genetica: 143-154.

Förster A (1869) Synopsis der Familien und Gattungen der Ichneumonen. Verhandlungen des Naturhistorischen Vereins der Preussischen Rheinlande und Westfalens 25(1868): 135-221.

Gauld ID (1991) The Ichneumonidae of Costa Rica, 1. Introduction, keys to subfamilies, and keys to the species of the lower Pimpliform subfamilies Rhyssinae, Poemeniinae, Acaenitinae and Cylloceriinae. Memoirs of the American Entomological Institute 47: 1-589. 
Ghahari H, Jussila R (2014) A faunistic study on the Ichneumonidae (Hymenoptera: Ichneumonoidea) from the west of Iran. Linzer biologische Beiträge 46(2): 1373-1377.

Jonaitis VP (1981) A guide to the insects of the European part of the USSR. Hymenoptera, Ichneumonidae. Subfam. Gelinae (Cryptinae). Opredeliteli Faune SSSR 129: 175-274. [In Russian]

Li T, Sheng M-L, Sun S-P, Chen G-F, Guo Z-H (2012) Effect of the trap color on the capture of ichneumonids wasps (Hymenoptera). Revista Colombiana de Entomología 38(2):338-342.

Luhman JC (1986) Revision of Nearctic Glyphicnemis Foerster (Hymenoptera: Ichneumonidae, Gelinae). Insecta Mundi 1: 133-142.

Sawoniewicz J (1985) Revision of European species of the subtribe Endaseina (Hymenoptera, Ichneumonidae), I. Annales Zoologici 39: 131-145.

Schwarz M, Shaw MR (2010) Western Palaearctic Cryptinae (Hymenoptera: Ichneumonidae) in the National Museums of Scotland, with nomenclatural changes, taxonomic notes, rearing records and special reference to the British check list. Part 4. Tribe Phygadeuontini, subtribes Mastrina, Ethelurgina, Endaseina (excluding Endasys), Bathythrichina and Cremnodina. Entomologist's Gazette 61: 187-206.

Townes HK (1970) The genera of Ichneumonidae, Part 2. Memoirs of the American Entomological Institute 12(1969): 1-537.

Uchida T (1930) Fuenfter Beitrag zur Ichneumoniden-Fauna Japans. Journal of the Faculty of Agriculture, Hokkaido University 25: 299-347.

Uchida T (1952) Einige neue oder wenig bekannte Ichneumonidenarten aus Japan. Insecta Matsumurana 18(1-2): 18-24.

Uchida T (1955) Die von Dr.K. Tsuneki in Korea gesammelten Ichneumoniden. Journal of the Faculty of Agriculture, Hokkaido University 50: 95-133.

Yu DS, van Achterberg C, Horstmann K (2016) Taxapad 2016, Ichneumonoidea 2015. www.taxapad.com 